\title{
La metamorfosis del lenguaje doméstico: La casa Tugendhat, 1928-30
}

\section{Metamorphosis of the domestic spatial language: The Tugendhat house 1928-30}

\author{
AURORA FERNÁNDEZ RODRÍGUEZ \\ Profesora titular interina. Departamento de Proyectos Arquitectónicos. \\ Escuela Técnica Superior de Arquitectura. Universidad Politécnica de Madrid \\ aurora.fdz@gmail.com
}

Recibido: 23/04/2016 Aceptado: 27/02/2017

\section{Resumen}

Este trabajo investiga sobre el lenguaje espacial doméstico que Mies van der Rohe elabora a través del proyecto y las publicaciones de la casa Tugendhat (1928-1930). Él superpone dos lenguajes espaciales en la casa, la planta libre y la articulación de volúmenes. Es en el uso de la planta libre donde su lenguaje sufre un cambio radical. Comienza a elaborar una serie de espacios a través de los objetos que no tienen asociados una función determinada. Estos lugares se componen con el mobiliario, los muros y el cerramiento, y representan los escenarios para la "vida de la casa". Usa la geometría de una malla virtual de pilares de acero en forma de cruz para fijar estos lugares y establecer relaciones que ordenan la planta. Los recorridos que se forman se asocian a los vacíos que dejan los escenarios y relacionan los lugares y los objetos. Estos elementos toman valor a través de la calidad de su construcción y de su material. Mies propone una nueva visión a través de la unión entre tecnología y artesanía que implica no sólo al material sino, a las técnicas de su transformación y afectan al valor de la experiencia de los escenarios domésticos. La percepción de estos lugares publicita lo doméstico y es a través de la transparencia del vidrio, de la luz y del reflejo que los objetos cobran "vida", se desmaterializan y extienden sus límites hasta expulsarlos del orden impuesto. Se convierten en "objetos extraordinarios". 


\title{
Palabras clave
}

Mies van der Rohe, Tugendhat, mapa, lugar, reflejo, metamorfosis, acontecimientos, "objetos extraordinarios".

\begin{abstract}
This work investigates on the domestic space language that Mies van der Rohe elaborates through the project and the publications of the house Tugendhat (1928-1930). It superimposes two spatial languages in the house, the free plan and the articulation of volumes. It is in the use of the free plan where his language undergoes a radical change. It begins to elaborate a series of spaces through objects that do not have associated a certain function. These places are made up of the furniture, walls and the enclosure and represent the stages for the "the house's life ". He uses the geometry of a virtual grid of cross-shaped steel pillars to fix these places and establish relationships that order the plan. The itineraries that are formed are associated with gaps left by the scenarios and relate places and objects. These elements take value through the quality of its construction and its material. Mies proposes a new vision through the union between technology and crafts that involves not only material but techniques of its transformation and affect the value of the experience of the domestic scenarios. The perception of these places advertises the domestic and it is through the transparency of glass, light and reflection that objects take "life", dematerialize and extend their limits to expel them from the imposed order. They become "extraordinary objects".
\end{abstract}

\section{Keywords}

Mies van der Rohe, Tugendhat, map, place, reflection, metamorphosis, events, "extraordinary objects".

Referencia normalizada: FERNÁNDEZ RODRÍGUEZ, AURORA (2017): “La metamorfosis del lenguaje doméstico: La casa Tugendhat, 1928-1930". Arte y Ciudad. Revista de Investigación, no 11 (abril), págs. 117-136. Madrid. Grupo de Investigación Arte, Arquitectura y Comunicación en la Ciudad Contemporánea, Universidad Complutense de Madrid.

Sumario: 1.- Introducción. 2.- Descripción. 3.- El lenguaje espacial: plano, mapa, lugar, acontecimientos. 4.- Los materiales. 5.- La vida de lo doméstico: objetos cotidianos - objetos extraordinarios. 6.- Bibliografía. 


\section{Introducción.}

Ludwig Mies van der Rohe y Lilly Reich reciben el encargo de la casa Tugendhat a finales del año 1928 de la pareja formada por Grete y Frizt Tugendhat, procedentes de familias acaudaladas de Moravia. La joven pareja reside en Brno y conocen al arquitecto a través del coleccionista de arte, Eduard Fuch residente en Berlín, en una casa primeriza de Mies, la Perls de 1912.

El solar de Brno ocupa la parte nordeste del jardín familiar de Grete Tugendhat y es el regalo de boda ${ }^{1}$ de sus padres.

Este proyecto ofreció a Mies y a Reich ${ }^{2}$ la posibilidad de materializar en detalle sus ideas arquitectónicas y de diseño de muebles sin ningún tipo de restricciones por parte de los clientes. El diseño de los jardines fue encargado a Grete Müller Roder.

El trabajo que desarrollan continúa el discurso hacia la transparencia y fluidez del espacio doméstico, en su relación entre interior y exterior ensayado anteriormente en el bloque de viviendas en la Weissenhof-Siedlung en Stuttgart de 1927, promovido por el Werkbund y en el Pabellón de Alemania para la Exposición Internacional de Barcelona de 1929. En su conjunto su propuesta para los Tugendhat, está llena de especulaciones y puntos de vista que amplían el significado del lenguaje arquitectónico.

\section{Descripción.}

Muchos críticos como Giedion, Tafuri, Dal Co o Frampton cuando analizan la casa Tugendhat, aluden a la transformación del sistema espacial utilizado en el Pabellón de Barcelona (1929) para adaptarlo sobre el terreno a un programa doméstico.

¿Pero cual es esa transformación espacial del espacio doméstico?

El emplazamiento de la parcela tiene unas condiciones muy concretas de partida que le obligan a trabajar con la volumetría, las vistas y los recorridos. Tiene una fuerte pendiente hacia la calle que termina en un muro de contención.

\footnotetext{
${ }^{1}$ Tegetthof (1985) afirma que no sólo fue el terreno el regalo de bodas sino que el regalo incluía toda la construcción de la casa.

${ }^{2}$ Lilly Reich era presentada como colaboradora de Mies en el diseño de interiores.
} 
Mies se ajusta al desnivel colocando la entrada desde la calle, orientada a norte, en la cota más alta y el acceso al jardín, orientado a sur, en la cota más baja de la parcela.

Al encajar la volumetría con el desnivel y los árboles del jardín tiene que resolver la presencia de la casa desde la calle y desde el jardín. Para ello, se retranquea del linde del vial creando una plataforma al nivel de la acera de llegada sobre la que emerge la casa, entendiéndose como una volumetría exenta de una planta. Para alcanzar el nivel de la calle eleva la casa desde el jardín sobre un podio, resolviendo la volumetría en tres plantas.

La planta superior de acceso contiene los espacios privados, las habitaciones y el garaje con habitaciones de servicio. Está formada por un conjunto de volúmenes dispuestos en aspa y articulados por la cubierta, organizando patios y vacíos en torno a sus volumetrías.

La planta baja incluye los espacios públicos de salón, comedor, biblioteca, jardín de invierno y los de servicio y cocina. La parte noble pública está definida dentro de un volumen nítido apoyado en el muro de contención y de planta libre en contacto por su lado este y sur con el jardín.

La planta en contacto con el terreno alberga las instalaciones y organiza el pódium, un plano preciso sobre el que surge la casa y la separa del suelo en la fachada sur del jardín.

La planta, rectangular de 55 × 17 metros cuadrados, es paralela a la calle en su lado largo. El desnivel del terreno generaba dos volúmenes muy distintos y desequilibrados, mientras que hacia la calle, la fachada era extremadamente horizontal, hacia el jardín con tres niveles organizaba una fachada muy vertical. Estas condiciones obligan a Mies a explorar soluciones volumétricas más equilibradas, acordes con funciones, vistas y orientaciones.

Esta decisión de invertir los espacios privados arriba y los públicos abajo le fuerza a repensar la envolvente respecto a las diferentes vistas, la casa desde la calle y la casa desde el jardín. En ellas, examina posibles modificaciones de la volumetría parcial y su impacto en el volumen general, de abajo a arriba, comienza con una pieza compacta y alargada conectada al jardín y coloca encima, unas piezas articuladas cerradas hacia la calle que se retranquean del perímetro y le permiten romper la horizontalidad y la verticalidad de sus fa- 
chadas. Estas piezas se expanden y contraen en diferentes direcciones y visualmente disminuyen el volumen generando visiones diagonales.

Desde la calle, Mies promueve la percepción en escorzo al remeter el volumen de las habitaciones con respecto al volumen del garaje. De este modo, ofrece un patio de entrada escalonado, en relación al nivel de la calle y entrada, que articula distintas vistas eliminando una relación lineal y directa con la calle. Se camufla la vista frontal de la fachada de entrada de la casa, creando un vacío entre volúmenes. Este vacío entre el volumen del garaje y la entrada principal suaviza la dimensión alargada.

Al colocar las habitaciones en la planta de arriba, gestiona el espacio de manera que las circulaciones privadas y públicas no se interfieran. Separa la zona de servicio y garaje de la entrada principal por un vacío. Establece dos circulaciones de muy diferente índole, la principal y la de servicio, colocadas sobre el mismo plano que se vinculan interiormente en el office de la cocina de planta baja, situado entre la escalera y el comedor ${ }^{3}$.

La puerta de entrada de la casa se esconde colocándola en un plano paralelo a la calle. Desde aquí, la puerta queda simbolizada por el umbral de entrada, generando un vacío que enmarca la vista lejana de la ciudad de Brno. Esta desaparición de la puerta en favor de la vista permite que la calle se prolongue sobre el espacio privado de la parcela y se oculte la idea casa ${ }^{4}$. El paso de la calle, a la entrada y a la puerta de acceso genera un recorrido que obliga a cambiar de ejes.

Mies investiga dos lenguajes espaciales domésticos que se colocan uno encima del otro, organizando las plantas, la planta abierta, libre y compacta frente a la planta cerrada y blanda formada por volúmenes fragmentarios entrelazados y articulados por la cubierta. La única conexión entre las plantas en

\footnotetext{
${ }^{3}$ Si comparamos la colocación de las habitaciones de servicio en villa Stein (1926) de Le Corbusier y las de la Tugendhat, vemos que responden a dos modelos diferentes. Mientras que Le Corbusier asocia las habitaciones de servicio a los niveles inferiores de planta en contacto con el suelo, Mies lo soluciona a través de las vistas y recorridos. Las habitaciones de servicio se orientan a una fachada independiente del cuerpo principal de la casa a pesar que se resuelve en el mismo nivel.

${ }^{4}$ Formalmente tiene gran relación con el bloque que Le Corbusier había realizado en Sttutgart para la Weissenhof-Siedlung un año antes, al que Mies había invitado. La planta elevada de terraza-jardín se resolvía con un marco que encuadraba la vista lejana.
} 
el interior, es la escalera semicircular, solada en mármol travertino y con cerramiento de vidrio curvo translúcido de suelo a techo que ilumina el hueco de escalera.

La planta de las habitaciones está formada por tres volumetrías cerradas que se disponen en esvástica y se enlazan a través de dos espacios vacíos dispuestos en diagonal de diferente carácter. Uno organiza un patio-terraza privado en torno a las habitaciones orientadas a sur; y el otro público, es continuación del espacio de la calle a norte.

La articulación de los volúmenes de la planta superior maneja una geometría menos rígida. Los espacios se van distribuyendo a través de un pasillo con forma de "s" extendida separando habitaciones de padres y habitaciones de hijos y de niñera. Las ventanas se encuadran en las fachadas entre particiones, los pilares metálicos se esconden en el cerramiento y las particiones ${ }^{5}$.

Esta planta de habitaciones y acceso se cierra hacia la calle, sólo el garaje se relaciona directamente, facilitando que el concepto de casa se oculte. Su solución transforma la casa en un foco de atracción, un mirador bien situado para contemplar un paisaje.

La planta baja se compone de pilares metálicos en forma de cruz vistos, forrados con diferentes acabados, cromados brillantes en el salón y espacios representativos, blancos en la cocina y color bronce al exterior.

Esta planta de salón, al tener los pilares a la vista contribuye a que el espacio se entienda isótropo, ordenado y pautado. Toda la envolvente sur y este se resuelven con una fachada de vidrio de grandes dimensiones que se extiende de suelo a techo y en la fachada este se duplica el cerramiento para incluir un jardín de invierno.

Para la apertura de estos grandes paneles de vidrio de la fachada sur se diseña un mecanismo eléctrico que recoge la carpintería de vidrio en el basamento. $Y$ en la fachada este, se proyecta una puerta de salida al jardín exterior.

El salón y todos sus espacios adyacentes se entienden como una extensión del jardín. La casa se prolonga por la transparencia de sus fachadas mas allá

\footnotetext{
${ }^{5}$ Fue deseo expreso de la familia que en la planta de habitaciones ocultase los pilares.
} 
de sus límites de vidrio ${ }^{6}$. Se convierte en un escenario ${ }^{7}$, un lugar donde se desarrolla la vida doméstica en contacto con el jardín.

\section{El lenguaje espacial: plano, mapa, lugar, acontecimientos.}

Mies y Reich parecen sugerir, que sólo en la planta del estar, biblioteca, jardín de invierno, y comedor se vuelquen con la creación de un lenguaje ${ }^{8}$ doméstico que reflexione sobre la era maquínica ${ }^{9}$, la abstracción y la nueva objetividad, Neue Sachlichkeit, que proponía un distanciamiento del autor con su obra, para compatibilizar la arquitectura con los objetos domésticos de producción estándar.

La representación del proyecto parte sobre la base de un espacio homogéneo definido por la trama de pilares y dentro se presentan unos lugares ${ }^{10}$ : el lugar comedor, el lugar piano, el lugar biblioteca y el lugar jardín de invierno. El esquema del plano pierde su contenido como representación exacta ${ }^{11}$ de su construcción para convertirse en mapa. Un mapa que representa la distribución y la organización de lugares de la casa y establece entre ellos relaciones a derecha y a izquierda, arriba y abajo, los límites de sus extensiones.

El juego de tantear lugares domésticos sobre el plano mediante objetos que representan a sillas, mesas y muros sobre un sistema espacial reticular presentado por cruces, genera un cierto orden. Este espacio ordenado toma valor cuando los lugares son practicados, es decir, toma sentido con las prácticas espaciales del habitante que refuerzan la equivalencia de casa, mapa y lugar.

\footnotetext{
${ }^{6}$ Sólo la parte noble de la planta tiene cierre de vidrio. La parte de servicio se cierra y se estratifica hacia el muro de contención teniendo una orientación oeste.

7 “Toda la vida de las sociedades en que reinan las condiciones modernas de producción se anuncia como una inmensa acumulación de espectáculos. Todo lo que antes era vivido directamente se ha alejado en una representación" (Debord, 1967).

${ }^{8}$ Según Philip Johnson (1947) es en el estar de la casa Tugendhat donde Mies nos ofrece un nuevo lenguaje con el uso de materiales caros.

9 Sociedad de producción de la "era de la máquina". Tomada la expresión de Guattari (1996).

10 “Lugar es el orden (cualquiera que sea) según el cual los elementos se distribuyen en relaciones de coexistencia.... Lugar es pues una configuración instantánea de posiciones. Implica una indicación de estabilidad" De Certeau (1990)

${ }^{11}$ Mies, sobre todo a partir del año 1924, en sus publicaciones, los planos no son representación de la realidad construida sino que dibuja un esquema lo suficientemente claro para ser modificable sin funciones: Ver casa de ladrillo o Casa de Hormigón publicados en G.
} 
En el salón se añaden elementos móviles que involucran al habitante en la transformación del espacio a través del accionamiento de cortinas de terciopelo negro y de seda y algodón de color natural, o al eliminar los planos de vidrio del cerramiento mediante mecanismos eléctricos que amplían el ámbito del interior de la casa en el exterior.

Se establece un marco de geometría abstracta, de retícula entre el suelo y el techo continuo blanco. Para introducir posteriormente los objetos, la realidad. Ellos forman los lugares que emergen de la estructura. Mies y Reich están investigando en la creación de unos emblemas, unas equivalencias visuales que incluyen muros, muebles, mesas, sillas, cortinas, alfombras que representan funciones domésticas biblioteca, comedor, estar....

Estas equivalencias son los desencadenantes de la "vida" de la casa en correspondencia con la época de una sociedad mecanizada y de consumo, donde el hombre consciente de lo engañoso de sus experiencias, de su fragmentariedad y de su fragilidad, ya no tiene vínculos concretos a necesidades relacionadas con funciones. Sólo el "deseo" es su potencia productiva de la vida12.

Ellos quieren llegar a una cualificación de las partes del edificio, partiendo del tipo general, para pasar a lo particular. Toman la abstracción como punto de partida y al hecho real como punto de llegada. Su objetivo es hacer visible los valores inherentes y las relaciones significativas, la naturaleza de los elementos que organizan el espacio doméstico ${ }^{13}$. La metáfora de la máquina no sólo comprende el funcionamiento del espacio sino también su expresión.

Los recorridos se componen por una serie de unidades en forma de vectores y atienden a direcciones, distancias, puntos de referencia. Son la base del

\footnotetext{
12 "Y sin duda nuestro tiempo prefiere la imagen a la cosa, la copia al original, la representación a la realidad, la apariencia al ser... Lo que es 'sagrado' para él no es sino la 'ilusión', pero aquello que es profano es la verdad. Más aún, lo sagrado se engrandece a sus ojos a medida que decrece la 'verdad' y que la ilusión crece, tanto y tan bien que el 'colmo de la ilusión' es también para él el 'colmo de lo sagrado'". Feuerbach, L. (1929): La Esencia del cristianismo (prefacio a la segunda edición en castellano).

13 "En este camino, la industria y la tecnología unirán sus fuerzas con el pensamiento y la cultura. Estamos en un periodo de transición, una transición que cambiará el mundo. Explicar y ayudar durante una transición será responsabilidad de las exposiciones futuras y sólo triunfarán si se concentran en esta tarea, y abordan el problema de nuestro tiempo: intensificar nuestra vida". Mies van der Rohe, L. (1928): Zumthema Ausstellungen Die Form 4.
} 
mapa, sobre la que se sitúan los indicadores que reflejan el lenguaje simbólico de las funciones. Se trata así, de producir un escenario donde cuestionar los propios hábitos, una infraestructura al servicio de la ficción del día a día.

Son espacios para estar en un movimiento constante y como puro observador de lo doméstico, el habitante no se siente identificado con el espacio, lo intuye, lo destruye y lo vuelve a construir, disipando la huella de lo individual. Se fomenta una experiencia especulativa del mundo: "Nos llevan a estar fuera de estas cosas que se quedan ahí indiferentes absolutas, nos provocan una sorpresa de su efímera y tranquila extrañeza" (De Certeau, 1990: 7).

Esta idea de proyectar lugares para la vida doméstica amplía el horizonte de la arquitectura, desplazándola hacia un terreno donde no hay usos, las actividades quedan relegadas a que el espacio de la casa ponga en relieve los objetos que conforman los escenarios domésticos. Como dice Juan Navarro Baldeweg, "ponga en relieve la especificidad de los objetos y en ellos se incluye a los materiales y elementos arquitectónicos". A través de estos objetos se vislumbra el significado de la producción y de la técnica que está asociada a la vida.

Exponer la "vida de la casa" consiste en la manifestación de una totalidad hecha por partes. Son unidades que intervienen como piezas relativas. Se trata de ofrecer universos matizados dentro de un campo mayor. Por ello, es muy importante primero el definir un campo de actuación -el recinto- y segundo las relaciones entre esos universos.

En este juego expositivo de presentación de "lugares" se superponen dos herramientas muy diferentes, una es la geometría que ordena los elementos arquitectónicos y objetos, y la otra es la observación de la diversidad a través de la materialidad y la manera de expresarlos en el lenguaje ${ }^{14}$. La geometría impone una ley que se aplica a los objetos que entran en esa composición donde cada objeto tiene asignado un sitio determinado, "la ley del lugarconstelación". Esta ley hace referencia a su representación en el plano ${ }^{15}$.

\footnotetext{
${ }^{14}$ La publicación de esta casa en el año 1931 contiene la misma información fotográfica en las distintas publicaciones en L'architecture vivant y Casabella.

${ }^{15}$ De la casa Tugendhat se guardan 400 bocetos en el Archivo del MOMA de los cuales los publicados en las revistas de la época y los constructivos difieren en pequeños detalles de lenguaje. Se borran elementos.
} 
Para que cada "lugar" sea posible, debe de existir un orden mayor que incluya a todos los lugares. Son el pautado de pilares que con su forma en cruz y envolvente redondeada en sus bordes tiende a hacer girar el espacio próximo y configuran el fluido o espacio intermedio. Tafuri y Dal Co (1989) definen este espacio como un laberinto, delimitado por el cerramiento de vidrio, el recinto. En el interior, el revestimiento de acero cromado brillante de los soportes crea un efecto de desmaterialización "que encubre su función estática" (Tegethoff, 1985).

El dibujo del plano de la casa hace que los objetos tomen presencia. Se asocian con una topología. En ausencia de los objetos, la trama de pilares configura vacíos y ritmos.

La obsesión de exponer tiene un afán de homogeneidad, libera el espacio vacío para un nuevo organismo que ha de servir como campo de acciones para "la vida de la casa". Así, el continente se neutraliza, se deja fluir.

De este modo la vida de la casa, el estar, se asemeja a la ciudad donde la realidad no era un lugar en sí, sino su desplazamiento, en un lugar que no era un lugar porque todo era fluido. Detenerse significaba ponerse una máscara dejar de ser real, dejar de tener sentido. Cuando se está inmóvil se forma parte del espacio. (Colomina, 2010).

Como apunte, la escultura de Lehmbruck que se adquiere para el salón después de 1931 se titula "Torso de una mujer caminando girándose" de 1914.

La combinación entre geometría que coloca inertes a los objetos en un lugar determinado con la observación de su materialidad a través del desplazamiento, disuelve los límites de los objetos, mezclando lo inmutable de los lugares con el efecto virtual de la luz. Así flotan, se estratifican, se producen cambios de escala con la reflexión, refracción de la luz, los reflejos y los brillos. Los materiales transparentes, vidrios de colores y espejos agreden al campo definido de la geometría del mapa y cada lugar se convierte en un acontecimiento.

Cada uno de estos lugares domésticos no se construye con elementos cotidianos. Los objetos expuestos se asocian a elementos de construcción de una casa convencional. Los objetos cotidianos son sustituidos por los elementos que construyen los escenarios. Mies, en su propuesta de la casa de ladrillo de 1924, usa el material para estructurar el organismo de la casa y los planos se dibujan sin funciones. 
Esta vivienda, cuya construcción está pensada en ladrillo, muestra la influencia que tiene el material en la forma de vida (...). En la planta baja de esta casa se ha abandonado el sistema habitual para delimitar los espacios interiores, con el fin de conseguir una secuencia de efectos espaciales en lugar de una serie de espacios singulares. En este caso, la pared pierde su carácter de cerramiento y sirve sólo para estructurar el organismo de la casa ${ }^{16}$.

Frente a los objetos técnicos que propugna Le Corbusier en la Maison Stein como el coche entrando en el garaje y en la cocina el termo, el ventilador, la cafetera y el pescado fresco extendido en la encimera; en la casa Tugendhat, aparecen el muro de ónice, el panel curvo de madera de ébano, las fachadas y divisiones de vidrio, la mesa de cristal, las sillas, la escultura del torso de una mujer caminando y la mesa de comedor. Mies propone una "artesanía experta" que contiene un agente colectivo, utiliza la mejor tradición para dar a los materiales la condición de pieza distintiva de las demás. Los materiales costosos y raros añaden un patrón de veracidad frente a la ilusión que produce un acabado superficial.

Cada material y cada forma llevan dentro las características del mundo del que ha sido tomado. El observador está forzado a encontrar el orden de los fragmentos, trazar relaciones entre ellos. Pero en la mayoría de los elementos es imposible encontrar esos nexos de unión, por ello, se encuentran en tensión. Esta tensión es el punto cero de la organización significativa ${ }^{17}$.

La representación de la planta no puede comunicar esta tensión existente entre la relación habitante y objetos, no traduce adecuadamente el edificio. Pierde su carácter exacto y por lo tanto su veracidad en favor de las vistas y fotografías. La planta estratifica la representación de los objetos sobre el plano del suelo que se vuelve transparente, suelo, alfombra, silla, mesa, muro, techo, cortina tienen un valor de cualificación del plano sobre el propio plano. La creación del lenguaje se realiza a través del dibujo que presenta en simultaneidad los elementos que componen el mapa.

Para Mies, la construcción de la casa es una consecuencia de la división del trabajo y es un mero lenguaje técnico, el arquitecto se convierte en artesano de los materiales que utilizará en la obra.

\footnotetext{
${ }^{16}$ Mies van der Rohe, conferencia, Manuscrito fechado el 19 de junio de 1924.

17 Whitehead, “Modos del pensamiento" 1938 (recogido en Millán, 2005).
} 
La fotografía publicita los lugares de la casa. Son la demostración universal y democrática en la que cualquiera puede desarrollar la vida de la casa, está destinada a cualquier morador para establecer sus lugares domésticos ${ }^{18}$. Para ello en los planos que se publican en revistas o se muestran en exposiciones se borra la información constructiva favoreciendo una información abstracta de los lugares, eliminando los condicionantes que impliquen una localización determinada y exacta. Se fijan unas figuras de equilibrio en las relaciones que se proponen entre objetos utilizando los ejes espaciales. A la escalera curva encerrada en el muro le corresponde otra figura curva girada 90 grados. Al banco del patio de juegos en la planta alta, le corresponde el muro curvo de ébano del comedor en la planta baja que se relaciona con el tronco del árbol que se ve casi frontalmente desde el comedor. Al volumen de habitaciones de padres le corresponde el volumen de habitaciones de hijos, colocados en paralelo. Al muro de ónice del estar le corresponde el muro de vidrio translúcido del espacio entre el office y el salón. Al muro de vidrio opal del salón le corresponden los cerramientos de vidrio del invernadero.

Los pilares parecen reproducirse mas allá de los límites de la fachada de vidrio, incorporando los troncos de los árboles de alrededor como nuevos sistemas de sujeción del espacio abierto.

\section{Los Materiales.}

Mies ha utilizado los materiales de una manera que parecen cada uno de ellos "obras de arte" en vez de elementos de la construcción, madera, mármol y vidrio. Usa la tecnología para normalizarlos y alcanzan un grado de únicos, proclamando un efecto de exclusividad. Todos sus materiales utilizan la máquina como sistema de corte y de unión. Esto acrecienta la uniformidad, por la mecanización de la producción y esconde la labor artesana basada en el respeto al material verdadero que incluye las herramientas y al fabricante.

Ruskin y Morris ya habían comentado las lamentables consecuencias de la máquina de producción en las actividades creativas y por lo tanto para la vida humana. Ellos creen que el hombre en cada proceso de trabajo debe de encon-

\footnotetext{
${ }^{18}$ Estos lugares se realizan con muebles y elementos muy pesados y difíciles de mover. Piénsese en el peso de la silla Barcelona, de 17 kilos, o en el sillón oscilador Tugendhat, de 18 kilos, o en el Lehmbruck, o en el muro de ónice doré.
} 
trar el placer del oficio, la experiencia de formarse y el arte para llegar a una existencia integrada (W. Morris, 1884).

El constructor está en una constante búsqueda del dominio científico, en renovar el contacto con los procesos naturales del orden de la naturaleza, con la pulsación de las fuerzas dinámicas a través de la dimensión tecnológica.

El artesano redescubre en cada trabajo la naturaleza de los materiales, sus dimensiones, sus cortes y su colocación a través de la tecnología y la repetición expresada en su textura, el crecimiento y su proceso de formación.

Mies desde su condición artesana, interpreta la imitación literal de roca en pared, conformada por la tecnología en un muro plano. De esta forma la imagen de la formación del yacimiento de la roca consolidado a través de los siglos por las fuerzas de la naturaleza, se purifica y se universaliza. Es fragmentaria porque el muro construido es la conversión de una roca en dimensiones geométricas cartesianas. Tiene un color poco usual, el ónice es color amarillo miel procedente de Marruecos, porque lleva implícito todo el proceso de formación de su origen pétreo, sus procesos químicos de fusión y cristalización de minerales, sus contenidos de aire y poros, sus debilidades en la fractura. Utiliza la precisión y la exactitud en la medida mínima de su espesor y en continuidad de sus partes.

Cada material sostiene en sí mismo el patrón de veracidad. La autenticidad y la coherencia de los materiales derivan otra vez de la transformación industrial de los minerales, rocas, y plantas vegetales. Reinterpreta como Ovidio declara al comienzo de La Metamorfosis: “...me lleva el ánimo a decir las mutadas formas a nuevos cuerpos". Estos cambios provienen de las combinaciones químicas y físicas de los cuatro elementos básicos de la naturaleza: el fuego, el agua, la tierra y el aire. En esta honestidad de transformación, el material evoluciona a una forma-tipo, entendida ésta como una categoría genérica tecnológica.

El material lo llevará hasta sus últimas consecuencias, al menor grosor y a la mayor amplitud. Necesita una reconfiguración orgánica, pues el cambio más insignificante modifica la relación de las partes. Hemos pasado del bloque, de la masa cúbica, a la planeidad del volumen. El plano curvado de ébano que proviene de Makassar, Indonesia ${ }^{19}$, nos evoca la materia del árbol y

19 Las maderas que utiliza para los muebles y los recubrimientos es de zembrano y de palisandro traídas del Sureste Asiático. 
su síntesis de forma en tronco. Esta configuración desvela el poder de la metáfora que tiene la metamorfosis de un árbol dentro de la casa y de las técnicas para la elaboración de símbolos constructivos que envuelven "la vida".

Mies no acepta la condición industrial como una realidad externa, quiere participar de una manera activa en ella. Igual que Miguel Ángel y los clásicos, no se conforma con la compra-venta del mármol, madera, seda y terciopelo ${ }^{20}$. Quiere seleccionar los materiales desde su origen:

...es una obsesión devoradora, destructora, que basta para paralizarme. Para combatirla trato de limitar el campo de lo que voy a decir, y de dividirlo en campos cada vez más limitados, para seguir subdividiéndolos, y así, sucesivamente. $Y$ entonces siento otro vértigo, el del detalle del detalle, lo infinitesimal, lo infinitesimalmente pequeño me absorbe, así como antes me dispersaba en lo infinitamente vasto (Calvino, 1986).

Busca en sus exploraciones proyectuales que las técnicas de reproducción creen nuevas condiciones para el artista, el público y los medios de producción.

Montar instalaciones y organizar exposiciones se convirtió para Mies desde 1924 en una de las actividades más importantes a través del Werkbund. En estas exposiciones, el lema de la organización se podría definir en estas cuatro cuestiones: Integrar los oficios tradicionales con las técnicas industriales de producción en masa, separar la estética de la calidad del material, imponer una normalización y adoptar la forma abstracta como base estética del diseño industrial sustituyendo al ornamento. Mies parece que ha coincidido con el Werkbund en que la calidad del trabajo le da un valor que trasciende el estilo.

Los principales acabados de la casa se ejecutan con las técnicas artesanales tradicionales, pero con un alto nivel de calidad a través de la máquina: Enlosados de mármol travertino pulido sin brillo en zócalos, hiladas de las escaleras del jardín y del pretil de la terraza superior, y, en el interior, en suelos y estantes de las paredes del vestíbulo, del invernadero y de la escalera de caracol.

De la unión de urdimbre y trama con la que están realizados algunos de los muebles de madera y telas de seda y terciopelo se pasa, en los muros divisorios, a un ensamblaje de mortaja y espiga, encajando dos piezas de madera entre sí, cortando el final de una dentro de la otra, a veces, realizando la inserción de manera oblicua lo que le exime de clavar. En otras se lamina la

${ }^{20}$ Seda y terciopelo son materiales influenciados, al igual que el uso de los colores, por Lilly Reich. 
madera, se yuxtaponen en capas pegadas que dejan ver la textura, la propia laminación produce un dibujo del material. Las tablas anchas (sobre todo las de corte tangencial) se comban en sentido contrario a los anillos de crecimiento, produciendo deformaciones estructurales en el tablero, de ahí el motivo de dividir en estrechos listones. De esta manera, los movimientos de retracción y turgencia se ven reducidos ganando estabilidad. La superposición de finas capas deja en el exterior su huella.

En el vidrio utiliza ciertos procesos industriales y componentes químicos para producir diferentes matices de color y curvaturas. Varía de totalmente transparente en sus fachadas a translúcido en su interior. Utiliza el "vidrio opal", el material de los anuncios nocturnos de las calles de Berlín y el vidrio curvado. Y usa esta pared de vidrio opal como iluminación efímera de la arquitectura doméstica de la noche.

El acero se dimensiona en toda su altura como un pilar exento de tres plantas. El forjado de las plantas le servirá para ampliar su rigidez. Unos se proyectan para ser embebidos en los muros, otros forrados. Su forma en cruz, atiende a su unidad como todos los demás materiales reunidos en torno a la casa, con una única dimensión.

El linóleum en el suelo del salón tiene un efecto fotogénico, es un producto que proviene del ámbar de los árboles, del corcho y del yeso. En el Werkbund lo promovía porque creaba ambientes luminosos y daba claridad a los objetos cuando el interior exigía un efecto delicado en el que flotase el mobiliario. En aquellos años sólo se usaba en baños y cocinas, y Mies y Reich lo amplían a los salones después de su exposición en Berlín ${ }^{21}$ para conseguir un suelo abstracto y continuo en correspondencia con el techo blanco.

Así piedra, madera, cristal, metal, telas de lino y terciopelo componen universos que se ponen en relación, cada uno con sus leyes. Se utilizan procesos que se adaptan perfectamente a la definición de máquina:

Una máquina se define como un sistema de cortes. No se trata de ninguna manera del corte considerado como una separación con la realidad; los cortes operan en las dimensiones variables siguiendo el carácter considerado. Toda máquina en primer lugar, está en relación con un flujo mate-

21 “Exposición del Linoleum del Werkbund” de 1929 Mies van der Rohe y Lilly Reich. Berlín. 
rial continuo (Hylè) en el cual ella corta... La Hylè designa, en efecto, la continuidad pura que una materia posee idealmente.... el corte no se opone a la continuidad, la condiciona, implica o define lo que corta como continuidad ideal. Pues como hemos visto, toda máquina es máquina de máquina. La máquina sólo produce un corte de flujo cuando está conectada a otra máquina que se supone productora del flujo. Y sin duda, esta otra máquina es, en realidad, a su vez corte (Deleuze, Guattari, 1998).

Se trata de tensar-destensar, contraer-dilatar, comprimir-explotar la física del material usado en la construcción. Comprende a las fuerzas activas, llamadas derivativas, relacionadas con la materia y a las fuerzas pasivas, o a la resistencia del material, la textura.

\section{La vida de lo doméstico: Objetos cotidianos - objetos extraordinarios.}

Le Corbusier en sus fotografías nos ofrece en Villa Stein o en Villa Savoie iconografías de la vida cotidiana, el pescado, la botella de leche, el habitante que en cualquier momento está a punto de aparecer. Mies nos ofrece lo nuevo, lo eternamente nuevo que no envejece porque el reflejo y los brillos funcionan como representación de lo "otro" 22 recordándonos que lo oculto permanece oculto, que la diferencia entre lo real y lo simulado permanece ambiguo, que la permanencia de las cosas siempre está en peligro en proceso de cambio.

Lo doméstico de Mies nos introduce en lo sublime dentro de lo cotidiano. Sus objetos de producción industrial desplazan "la vida", la función doméstica, al consumo supuestamente pasivo de sus productos convertidos en muros, envolventes de vidrio, suelos, techos, muebles y pilares. "El reflejo de los objetos" es una mirada a lo doméstico desde la lejanía, desde la idealización y la perspectiva crítica que otorga la distancia sobre el "propio terruño" y la necesidad de reconstruir la historia de los últimos tiempos y de su cultura ancestral. Son los "objetos sin escala" (Muñoz, 1989) con los que se construye la casa y al mismo tiempo "obras de arte" y objetos de "vida cotidiana": "Arte y vida" que Mies traduce en "arquitectura y construcción".

En 1930 hubo una polémica en la revista Die Form suscitada por Justus Bier y contestada por Walter Riezler sobre si se puede o no vivir en esta casa. Su argumento era que no se puede vivir en una obra de arte. Para Riezler, las

${ }^{22}$ Es un símil a la película de Los Otros de Alejandro Amenábar. 
nuevas ideas sugeridas en la casa Tugendhat superaban el concepto de lo que él denominaba "funcionalidad meramente útil" y satisface un concepto de funcionalidad que va más allá. Se basa en las modernas necesidades intelectuales y espirituales. En cambio para Justus Bier, la calidad del diseño de esta "obra de arte" se impone sobre otros conceptos funcionales e impediría un uso cómodo de la casa. Según Bier, no sería posible vivir en una obra de arte. "Con la casa Tugendhat, Mies daba una interpretación de la vivienda que era simultáneamente celda y mundo, centro de recogimiento y al mismo tiempo, lugar que se abría al mundo"23.

La mirada de la vanguardia en la arquitectura doméstica se realiza implicándose con los medios de comunicación de masas, la fotografía, la publicidad, la propaganda, las publicaciones.

El matrimonio Tugendhat ante la polémica, aporta una serie de fotografías que son testimonio de la vida de la casa. Publicitan escenarios domésticos, continuando los aportados por Mies en las publicaciones. Este debate sondea a los clientes en el uso del espacio.

El interés radica, en la función doméstica de la casa como un contrapunto, se proponía la "exposición" de una serie de escenarios que servían para la "vida" y se basaban en la individualidad de los elementos. El sistema se ligaba por relaciones geométricas abstractas entre piezas en la permanente tensión propia de lo incompleto que deriva de su actividad expositiva. Se advierte que la fotografía del salón donde aparece el muro de ónice amarillo miel publicada en L'Architecture Vivant es manipulada hasta convertir el muro de ónice en un espejo y el mueble bajo de madera y vidrio deja ver el espacio detrás de él.

Con la observación, el habitante transgrede la ley del lugar y despierta a los objetos mediante los fenómenos, la luz, el viento, la propia experiencia del recorrido de los lugares. Se establece una narración que no sólo afecta a "ver" sino a cómo los sentidos establecen relaciones con los objetos. Esta transgresión a lo que ha fijado la geometría en el espacio afecta a los objetos, que están colocados con un mismo valor en una tabula de equivalencias.

La observación en ese circular presupone un telón (cristal) sobre el que los objetos se colocan. Es la sucesión de acontecimientos. Tiene que ver con el

${ }^{23}$ Riezler, Walter (1931): Die Form no 6 (en Neumeyer, 1991: 288). 
cómo se ve y la tecnología asociada a los propios objetos, la técnica. La propia presentación de los objetos trae consigo conocer el qué y el cómo se exponen los elementos pertenecientes a la misma colección. Es una experiencia especulativa del mundo. Ahí es donde el reflejo, la luz, el brillo, entran en juego de cada lugar fijado. Son mutaciones de la apariencia, la vista hace y deshace. Contamina las relaciones que mantienen entre ellos, estos puntos fijos en el espacio. El punto de vista se convierte en una serie infinita de geometrías. La visión de la espacialidad se estratifica.

La geometría multiplicada y la división infinita de la materia, hace que la fuerza compresiva relacione cualquier porción de materia con los ambientes, con las partes circundantes que bañan y penetran el cuerpo considerado. Los lugares se disuelven ante el campo de acciones, aparece lo sublime, en el sentido de extrañamiento. Se domestica el exterior que queda interiorizado.

Esta situación de domesticidad que Mies adelanta: “Estar fuera de sitio, incluso en el lugar de residencia" (Benjamin, 2006), se convierte para él en una opción ética, en concordancia con lo que Theodor W. Adorno afirma en su autobiografía intelectual, Mínima moralia: "Pertenece a la moral no sentirse en casa al estar en casa".

Se considera que la única manera para entender la vida secreta de un lugar, la casa, es el extravío, e intuye que la experiencia del mundo tiene un sustrato perceptible a través de la "iluminación profana".

Lo doméstico de la casa ha producido un universo donde el hombre "debe por fin, despertarse de su sueño milenario"; y al "despertarse" en su completa soledad, en su aislamiento fundamental, se da cuenta que, como un gitano, vive en la frontera de un mundo extraño. Jacques Monod en El azar y la necesidad, escribe: "En adelante el hombre será considerado un observador separado en un universo que le es ajeno; torturando a la naturaleza hasta arrancarle sus secretos, porque saber es poder".

El lenguaje de Mies construye una serie de escenarios que incluyen unas estructuras disipativas que a través de transparencias y de reflejos, fluctúan hasta implicar una reorganización total. El hombre entonces deja de ser un espectador pasivo de estos espacios. Invitan a una reflexión sobre la sorpresa de estar en un espacio cambiante en el que ningún objeto que lo compone se mueve sin embargo, se expanden hacia el exterior. 
En la lógica de los signos, como en la de los símbolos, los objetos ya no están vinculados en absoluto con una función o una necesidad definida. Precisamente porque responden a algo muy distinto que es, o bien la lógica social, o bien la lógica del deseo, para las cuales operan como campo móvil e inconsciente de significación.

Cada objeto de la casa ha formado un acontecimiento, se vuelve $\operatorname{signo}^{24} \mathrm{y}$ se convierte en objeto de consumo. La función pierde interés en favor de su exhibición y su experiencia. Representan socialmente, sus objetos "extraordinarios".

Pero en la cultura ordinaria de lo doméstico, como dice Certeau "el orden es puesto en juego por el arte del consumo". Éste se encuentra disperso pero se insinúa en todas partes, silencioso y casi invisible, pues no se señala con productos propios sino en las maneras de emplear los objetos impuestos. Estos objetos que Mies, con la colaboración de Reich, han transformado en acontecimientos que conforman los escenarios de la vida doméstica.

\section{Bibliografía.}

AAVV., (2001): Mies in Berlin (publicado en relación con la exposición del mismo nombre) en MOMA. New York/Berlín.

BENJAMIN, Walter (2006): Libros de los Pasajes. Ed. R. Tiedemann Akal. Madrid.

CERTEAU, Michel de (1990): L'invention du quotidien. Arts de faire I. Gallimard. París.

COLOMINA, Beatriz (2010): Privacidad y publicidad. La arquitectura moderna como medio de comunicación de masas. COAMU, Murcia.

_ (2009): "La casa de Mies: exhibicionismo y coleccionismo". En 2G: Mies van der Rohe. Casas. nº 48-49. Gustavo Gili. Barcelona.

CALvinO, Italo (1980): Seis propuestas para el último milenio. Siruela. Madrid.

De Certeau, M. (1990): L'invention du quotidien. Arts de faire 1, Gallimard, Paris.

24 “Lo que el concepto es para el conocimiento de las cosas, el mecanismo, el instrumento, la máquina, lo son para una empresa práctica. Lo que el concepto procura al conocimiento, como medio para comprender muchos objetos, como signo que refleja con exactitud todos los rasgos comunes, esta misma función desempeña la máquina respecto a la acción. La máquina es un concepto de acero. Este se aplica a muchos objetos sin consideración a su carácter singular y concreto, como si todos ellos fueran idénticos. El proceso de una máquina reviste un carácter semejante al pensamiento conceptual. Ambos dominan las cosas, rompiendo la relación vital con lo individual, encuadrando todas las cosas en signos, creando así una vida artificial en la que todas las cosas se parecen". Romano Guardini, 2013: Cartas del Lago de Como. EUNSA. Pamplona. 
DEBORD, Guy (1967): La société du spectacle, Buchet-Chastel, Paris.

DeleuZe, Gilles y GuATTARI, Felix (1998): Anti Edipo. Paidós Ibérica. Barcelona.

DreXLER, A. y SCHUlZE, F. (1986): The Mies van der Rohe archive. Vol. 1-5 (catálogo comentado). Garland, Nueva York.

GASTÓN GUIRAO, Cristina, (2005): Mies: el proyecto como revelación del lugar. Fundación Caja de Arquitectos. Barcelona

GUATTARI, Félix (1996): Chaosmosis, Manantial, Buenos Aires, Argentina.

JOHNSON, Ph. (1947): Mies van der Rohe. MOMA. New York.

MilLÁN LÓPEZ, Juan (2005): “El regalo de los Low Beer", revista RA 07, pp. 41-52, Pamplona.

Miller, Wallis (1999): Tangible Ideas: Architecture and the Public at the 1931 German Building Exhibition in Berlin. Tesis Doctoral. Faculty of Princenton University, New York. www.research gate.

MONOD, Jacques (1981): El azar y la necesidad. Tusquets editores. Barcelona.

MORRIS, William (1884): Art and Socialism (es el texto de una charla pronunciada ante la Sociedad Secular de Leicester, Inglaterra). Traducida en febrero de 2014, en html para marxists.org: Rodrigo Cisterna.

MuÑoz, María Teresa (1989): “La casa Tugendhat: el canon de lo moderno". En Cerrar el círculo y otros escritos. COAM. Madrid.

NAVARro BAldeWeG, Juan (2001): La habitación vacante. Pretextos. Madrid.

_ (2007): Una caja de resonancia. Pretextos. Madrid.

NeumeYer, Friz (1991): The Artless Word: Mies van der Rohe on the Building Art. Cambridge Mass.

QUeTGLAS, Josep (2004): Artículos de ocasión. Gustavo Gili. Barcelona.

SCHUlZE, Franz (1985): Mies van der Rohe una biografía crítica. Hermann Blume. Barcelona.

TAFURI, Manfredo y DAL CO, Francesco (1989): Arquitectura Contemporánea. Ed. Aguilar, Madrid.

Tegethoff, Wolf (1985): Mies van der Rohe. The Villas and Country houses. MOMA \& MIT press. Massachusetts.

WhiteHEAD, Alfred N. (2009): “Modos del pensamiento" en Negro PAVÓN, Dalmacio: El mito del hombre nuevo. Ed. Encuentro, Madrid. 